\title{
Rationale and design of a type 2 diabetes prevention intervention for at-risk mothers and children at a Federally Qualified Healthcare Center: EPIC El Rio Families Study Protocol
}

David G. Marrero ${ }^{1}$, Robert M. Blew ${ }^{2,3}$, Kelly N. B. Palmer ${ }^{1}$, Kyla James ${ }^{4}$, Denise J. Roe ${ }^{5}$ and Melanie D. Hingle ${ }^{2,3^{*}}$ (D)

\begin{abstract}
Background: Exposure to gestational diabetes mellitus (GDM) is associated with increased risk for type 2 diabetes (T2DM) in mothers, and poor cardiovascular health among offspring. Identifying effective methods to mitigate T2DM risk has the potential to improve health outcomes for mothers with a history of GDM and their children. The goal of the EPIC El Rio Families Study is to implement and evaluate the effects of a 13-week behavioral lifestyle intervention on T2DM risk factors in at-risk mothers and their 8- to 12-year-old children. We describe herein the rationale for our specific approach, the adaption of the DPP-based curriculum for delivery to patients of a Federally Qualified Health Center (FQHC), and the study design and methodology.

Methods: The effects of the intervention on reduction in excess body weight (primary outcome), hemoglobin A1c, blood pressure, and changes in lifestyle behaviors associated with weight trajectory and T2DM risk in mother-child dyads will be evaluated during a 13-week, group randomized trial wherein 60 mothers and their children will be recruited to the intervention or wait-listed control conditions at one of two FQHC locations. Intervention participants $(n=30)$ will begin the group program immediately, whereas the wait-listed controls $(n=30)$ will receive a booklet describing self-guided strategies for behavior change. Associated program delivery costs, acceptability of the program to participants and FQHC staff, and potential for long-term sustainability will also be evaluated.

Discussion: Successful completion in our aims will produce a scalable program with high potential for replication and dissemination, and estimated intervention effects to inform T2DM prevention efforts on families who use the FQHC system. The results from this study will be critical in developing a T2DM prevention model that can be implemented and scaled across FQHCs serving populations disproportionately burdened by T2DM.

(Continued on next page)
\end{abstract}

\footnotetext{
* Correspondence: hinglem@email.arizona.edu

${ }^{2}$ Department of Nutritional Sciences, College of Agriculture \& Life Sciences, The University of Arizona, 1177 E. 4th Street, Shantz Building, Room 328, Tucson, AZ 85721, USA

${ }^{3}$ University of Arizona Collaboratory for Metabolic Disease and Prevention, Abrams Public Health Center, 3950 S. Country Club Rd, Tucson, AZ 85714, USA

Full list of author information is available at the end of the article
}

(c) The Author(s). 2021 Open Access This article is licensed under a Creative Commons Attribution 4.0 International License, which permits use, sharing, adaptation, distribution and reproduction in any medium or format, as long as you give appropriate credit to the original author(s) and the source, provide a link to the Creative Commons licence, and indicate if changes were made. The images or other third party material in this article are included in the article's Creative Commons licence, unless indicated otherwise in a credit line to the material. If material is not included in the article's Creative Commons licence and your intended use is not permitted by statutory regulation or exceeds the permitted use, you will need to obtain permission directly from the copyright holder. To view a copy of this licence, visit http://creativecommons.org/licenses/by/4.0/ The Creative Commons Public Domain Dedication waiver (http://creativecommons.org/publicdomain/zero/1.0/) applies to the data made available in this article, unless otherwise stated in a credit line to the data. 
(Continued from previous page)

Trial registration: ClinicalTrials.gov NCT03781102; Date of registration: 19 December 2018.

Keywords: Diabetes, gestational, Mothers, Diabetes mellitus, type 2, Life style, Body weight, Child, Primordial prevention, Preventive health

\section{Background}

Type 2 diabetes (T2DM) continues to be a major public health problem in the United States, with over 30 million persons afflicted and estimates projecting a continued increase $[1,2]$. Youth comprise a small yet growing number of new T2DM cases, with significant increase in overall incidence observed between 2002 and 2015 [3]. Major advances have been made toward understanding risk factors for T2DM and pathophysiology in youth. Dissemination of family-focused T2DM prevention programs to community settings remains rare, and a majority of programs have not directly involved parents or focused on youth who are at greatest risk. Thus, prior efforts have often resulted in diffuse interventions and insufficient implementation of lifestyle changes at home, as parents exert significant influence over the home diet and physical environment and opportunities [4-10]. The paucity of effective T2DM prevention programs adapted for delivery to at-risk families in accessible, affordable, and safe settings remains a critical barrier to reducing population prevalence and risk.

Herein we describe a study designed to address gaps specific to T2DM prevention for women with a history of gestational diabetes mellitus (GDM) and/or prediabetes and their 8- to 12-year-old children, who are nearly twice as likely to develop T2DM before the age of 22 compared to youth with no maternal GDM diagnosis [11]. This intervention study, Encourage, Practice, and Inspire Change in El Rio Families (EPIC El Rio Families), will engage those at greatest risk for T2DM, provide evidence-based intervention content and strategies to support lifestyle behavior modification, and leverage extant medical infrastructure and personnel for program delivery to address key social determinants of health as well as maximize future program impact and sustainability in the home $[12,13]$.

The goal of the EPIC El Rio Families project is to implement and evaluate the effects of a behavioral lifestyle intervention on T2DM risk factors in at-risk mothers and their children delivered within a Federally Qualified Health Center (FQHC) by trained FQHC personnel. Leveraging an $\mathrm{FQHC}$ network serving 110,000 underinsured and uninsured patients for intervention delivery provides an opportunity to take an efficacious T2DM program to scale. The FQHC participating in this study serves those among the highest risk for T2DM in the Southwestern region of the United States: low-income women previously diagnosed with gestational diabetes mellitus (GDM) or who have confirmed pre-diabetes (HbA1c of 5.7-6.4\%), and their child, aged 8- to 12years-old, who by virtue of genetics, pre- and post-natal exposures, and weight status, are also at significantly increased T2D risk [14, 15].

Up to $10 \%$ of pregnancies are affected by GDM, and the prevalence of GDM is increasing among pregnant women as obesity continues to increase [16, 17]. Among Hispanic women of Mexican origin, GDM is more common than non-Hispanic whites and its prevalence has increased since 2006 [18, 19]. In addition to the increased T2DM risk experienced by women with a history of GDM, there is growing evidence that maternal obesity and GDM are contributing to the increase in obesity and T2DM in their children [20, 21]. In the SEARCH for Diabetes in Youth study, intrauterine exposure to maternal diabetes and obesity was attributed to T2DM in $47.2 \%$ of the adolescent cohort [3], indicating that exposure to GDM is a strong predictor of T2DM development. Additionally, it is now known that hereditary risk for prediabetes and T2DM is impacted by common genetic variations associated with risk for developing $\beta$-cell dysfunction affecting insulin sensitivity [21]. These genetic factors combined with increasing levels of obesity-related insulin resistance are central components in T2DM development. Collectively, these facts enable us to convey to mothers who have had GDM that their children have an increased risk for developing T2DM, especially if excessive weight gain is not prevented.

There is now considerable evidence that lifestyle modification interventions that promote modest weight loss and increased physical activity can substantially reduce the risk for developing T2DM in adults [22-24]. There remains, however, a dearth of rigorously tested T2DM prevention lifestyle strategies for high-risk youth. This is due, in part, to the relatively low prevalence of T2DM in adolescents when compared with adults, and the complexity and costs associated with conducting such trials. In the absence of a definitive T2DM prevention study with youth at increased risk, lifestyle modification to support healthy eating and physical activity, thereby optimizing weight gain trajectories and insulin sensitivity, is the generally accepted mechanism to decreasing risk. In this context, the family-based behavioral approach is the standard model for preventing and treating 
childhood obesity and associated health risks. Indeed, prior research has established that interventions featuring parents as primary change agents had better outcomes to traditional child-only focused approaches [2529] and offer potential for sustainability and costeffectiveness.

We contend that mothers at increased risk for T2DM in combination with their child should be the focus of an intervention to decrease familial T2DM risk, and further, that counseling mothers about the T2DM health risks in combination with strategies to reduce these risks increase the likelihood of sustained changes to lifestyle behaviors and the home environment that will support risk reduction. We hypothesize that the delivery of a T2DM prevention program emphasizing lifestyle modifications in families to reduce weight, improve diet quality, increase physical activity, and manage stress for high-risk mothers would also benefit their children.

\section{Methods/design \\ Adaptation of a diabetes prevention curriculum for EPIC El Rio Families}

The intervention duration, content, and activities, designed to support families in meeting national recommendations were drawn from the intervention literature $[30,31]$ and our previous work [32-34]. Intervention "dose" (duration $\times$ time) was modeled after the successful adult-focused Diabetes Prevention Program [35] and the 2017 U.S. Preventive Services Task Force (USPSTF) evidence-based recommendations for weight loss, behavior change, and cardio-metabolic risk reduction in youth [36].

EPIC El Rio Families is intended for families served by El Rio Community Health Center (hereafter, El Rio), a Federally Qualified Health Center in the Southwestern United States serving more than 110,000 underinsured and uninsured patients, and a research partner in this study. El Rio patient demographics (85\% Hispanic or Latina (84\% White, 16\% American Indian), 15\% nonHispanic (80\% White, 11\% Black, 6\% Asian, 2\% Pacific Islander, $1 \%$ American Indian); more than $90 \%$ will live at or below the federal poverty level) and our formative work [37] suggest that the study sample will be majority-Hispanic, of whom at least one-third will prefer to participate in Spanish-only groups. Prior to implementation, language and cultural adaptations of intervention content were guided by focus groups conducted with women patients of El Rio [37]. Findings from focus groups prompted translation of all materials into Spanish, delivery of the intervention by bicultural, bilingual coaches, and culturally-sensitive diet and physical activity recommendations that do not violate cultural beliefs and practices.
Intervention sessions will be group-based, attended by up to 15 mother-child dyads, and led by a minimum of two trained bilingual FQHC health and wellness staff. Each session is approximately $2 \mathrm{~h}$ in length and was designed for delivery over 16 consecutive weeks at one of two El Rio locations. Total duration was shortened to 13 weeks following formative research to accommodate school and holiday scheduling demands, with optional booster sessions following the core 13-week program.

The intervention content is focused on practical strategies for modifying the behaviors associated with the pathogenesis of T2DM [38], including availability and accessibility of nutrient- and calorie-dense foods and food preparation strategies in the home, reducing intake of sugar-sweetened beverages, increasing time spent in physical activity and decreasing time spent in sedentary activities, stress management, and obtaining quality sleep (Table 1). Participants will be engaged in learning through interactive food demonstrations, energy balance activities (e.g., label reading, shopping preparation and planning), and physical activities appropriate for the entire family. Sessions provide repeated opportunities to practice healthy lifestyle behaviors. All activities incorporate evidence-based behavior change techniques and behavioral targets $[39,40]$. Each session follows a similar format consisting of the following five components: a featured physical activity encouraging families to get moving upon arrival; small group discussions focused on goal-setting and building intra- and inter-family camaraderie; food demonstration and tasting opportunities centered around increasing dietary fiber (vegetables, whole grains, and legumes) and reducing added sugar intake; group activities to increase foundational knowledge and skills related to healthy food selection, physical activity benefits, and creating a supportive home environment; and, opportunities to set new weekly goals or revise previous goals. Mothers and children are divided into two groups, with children engaged in games-based physical activity while mothers engage in discussions with program leaders and other participants regarding implementation of realistic, effective plans for family lifestyle behavior change and the use of proactive food and physical activity parenting practices [41]. Every third session, a behavioral health specialist will lead stress management exercises for all family members.

To reflect what will be the standard operating procedures for future implementation and expansion of the program, El Rio will select individuals to become lifestyle intervention coaches following extant procedures used by the organization. Criteria for consideration include recommendation by supervisors or colleagues, previous experience and comfort level working with children and families, organizational skills, and commitment to coaching participants through 13 consecutive weeks of 
Table 1 EPIC El Rio Families Program

\begin{tabular}{ll}
\hline Session & Session Topics \\
\hline 0 & What to expect/meet your coaches; setting goals \\
1 & Basic diabetes prevention; energy density of foods \\
3 & Making healthy food available and accessible in the home; how to prepare and enjoy vegetables, whole grains, legumes \\
4 & Swap screen time for active time; what is physical activity and why is it important? \\
5 & Serve just the right amount of food to keep body weight healthy; MyPlate \\
6 & Have more fun staying active as a family; benefits of family physical activity \\
7 & Enjoy calmer, healthier, more relaxed meals; making mealtime family time \\
8 & How to choose tasty, low-kcal beverages and drink less sugary drinks; label reading \\
9 & Learn and practice healthy sleeping habits and manage stress \\
10 & Eating out and making healthy choices; problem-solving \\
11 & Increase the variety of physical activity; overcome barriers to being active \\
12 & Making family physical activity happen; problem-solving \\
13 & Talking back to negative thoughts \\
\hline
\end{tabular}

programming. Coaches are also encouraged to become certified in group fitness and health coaching and receive instruction on core nutrition concepts related to T2DM prevention. This approach reflects how El Rio already implements and trains staff to conduct their adult weight management and T2DM treatment programs.

Select staff are then trained to be lifestyle coaches using the approach developed by the EPIC El Rio Families Study MPI and used by the CDC National DPP [35, 42]. This 3-day training process has been successfully used to train hundreds of lifestyle coaches [43] using standardized training materials including a comprehensive lifestyle coach manual. The manual will be modified to reflect new elements of the curriculum specifically designed for EPIC El Rio Families and include a section to support FQHC staff who wish to conduct additional trainings to help ensure standardized program delivery.

\section{Evaluation of the EPIC EI Rio Families Study}

This study uses a group randomized design to compare two groups of mothers who have had GDM or have been diagnosed with prediabetes, along with their children, who are between 8 - and 12-years-old. The goal is to recruit 60 mother/child dyads to either the EPIC El Rio Families intervention or wait-listed control conditions. To identify potential participants with histories of GDM and/or prediabetes who are patients at El Rio, we will query the FQHC's electronic health record (EHR). Women with a history of GDM during any of their pregnancies and/or a prior diagnosis of prediabetes and who have children 8 - to 12 -years-old at time of study will be contacted by phone and mail and invited to participate in EPIC El Rio Families. The participating child must be a biological child but does not have to be the direct product of a pregnancy with GDM. With attention to the composition of the FQHC patient population, the study sample will reflect majority Hispanic women from lower income groups.

Two El Rio clinics (A and B) have been selected to participate in this pilot study. Randomization to the intervention and wait-list control conditions will be performed by site using flip of a coin. Randomization by site has the least potential for contamination during the initial delivery period. Upon confirming respondent eligibility and obtaining written informed consent/assent, the research coordinator will match participants to the intervention site geographically nearest to their home, assign a study ID, and schedule baseline measurements. Following measurements, intervention participants will begin the 13-week face-to-face group program immediately, whereas the wait-listed controls will receive information about the offer to participate in the intervention after the first implementation and that they will continue to receive standard of care including access to nutritional counseling if desired. After 13 weeks, the intervention participants will transition to a follow-up phase while the wait-listed controls will begin the intervention (Fig. 1). Blinding is not possible with this design.

This design is responsive to standards of care for T2DM prevention [44] and will provide the opportunity to investigate pre-/post-intervention effects, intervention versus control effects, and maintenance effects. The number of participants and design also allow us to evaluate processes critical to successful implementation by El Rio, informing future replication and the potential scaling of the intervention to other sites in this and other FQHC networks. This clinical trial (ClinicalTrials.gov identifier NCT03781102) has been approved by the 


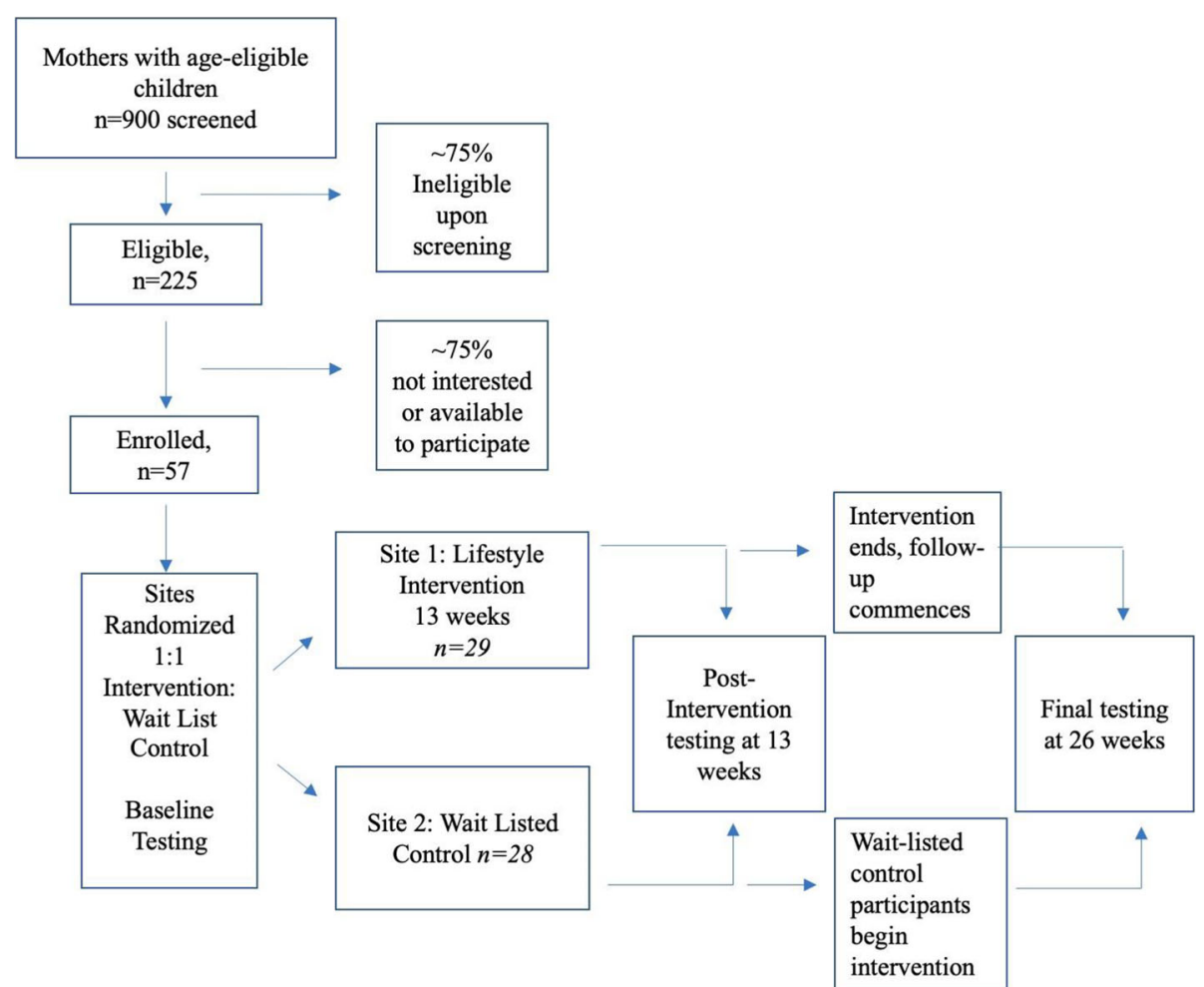

Fig. 1 EPIC El Rio Families Participant Anticipated Enrollment and Study Design

University of Arizona Institutional Review Board and all participants will provide informed consent or assent prior to participation.

Changes in percent weight for the mothers and changes in the BMI z-score for the children are used to confirm that there is adequate statistical power with the sample size of $n=60$ dyads. For mothers, the calculation is based on the observed change in the DEPLOY study for both sexes [34]. The mean change in body weight after 6 months was $-6.0 \%$ (standard deviation $=4.0 \%$ ). For children, the calculation is based on data from the EPIC Kids Study in which the mean change in BMI zscore was 0.054 (standard deviation $=0.02$ ) [32]. The power calculation assumed that in each period (intervention versus wait-list control) there will be 3 groups with 10 dyads per group ( $n=30$ intervention versus $n=30$ wait-list control). The statistical power is $>80 \%$ for the mothers and $95 \%$ for the children assuming an intragroup correlation or 0.15 or below (two-sided alpha level of 0.05$)$. As this is a pilot study to provide estimates for a larger trial, there is no adjustment for multiple comparisons.

The primary outcome is percent change in body weight and BMI at 13 weeks (post-intervention) and 26 weeks (follow-up/weight maintenance). Body weight and height will be measured using a calibrated, digital scale with a mechanical height rod and a stadiometer. Adult
BMI is categorized using international classifications of BMI (overweight, 25-29.9 kg/m²; obese, > $30 \mathrm{~kg} / \mathrm{m}^{2}$ ) [45]. In children, BMI percentile is determined using age- and sex-specific growth charts developed by the CDC in 2000 [46]. Lacking a gold standard for measuring change in weight status in children, we will use the recommended BMI z-score change, which has been established as a good proxy for fat mass z-score change [47]. Child and adult waist circumference, linked to metabolic syndrome in both populations, will be measured at the umbilicus. All measures will be completed in duplicate, and the average of the two measures will be used. Secondary physiological outcomes in children and mothers include changes in blood pressure and hemoglobin A1c (HbA1c). These data will be collected using portable, CLIA approved technologies. The definition of hypertension will be adjusted for age per national guidelines $[48,49]$.

Secondary behavioral outcomes associated with weight trajectory and T2DM risk in children and mothers will be assessed at 13 weeks (post-intervention) and 26 weeks (follow-up/weight maintenance). Child dietary intake will be assessed with two, nonconsecutive, intervieweradministered 24- $h$ dietary recalls conducted telephonically by trained nutritionists and entered into the Nutrient Data System for Research (Minneapolis, MN, v. 
2012) [50]. Overall diet quality and its components (total vegetables, whole fruit, whole grains, plant, animal, and seafood proteins, fats, sodium, sugar, and refined grains) will be calculated using the Healthy Eating Index-2015, a valid and reliable measure of diet quality designed to assess the degree to which an individual's intake conforms to dietary recommendations $[51,52]$. Child moderate to vigorous physical activity and sedentary behavior will be assessed using the Youth Activity Profile, a selfadministered 7-day (previous week) recall questionnaire validated for use in children ages 8- to 12-years-old [53] that includes 15 items divided into three sections: activity at school, activity out-of-school, and sedentary. Sleep behavior will be assessed using the Children's Sleep Habits Questionnaire, Abbreviated, a 22-item survey designed for parent report of key child sleep domains that encompass major medical and behavioral sleep disorders in school-aged children [54]. Maturity will be assessed from a self-report of Tanner's breast/genital and pubic hair descriptions. The validated questionnaire presents illustrations of developmental stages shown to agree with pubertal staging by a physician [55].

Parental dietary intake will be assessed using the validated Arizona Food Frequency Questionnaire, a selfadministered semi-quantitative 159-item questionnaire in which respondents report how often they typically consume specific foods and food groups and associated portion sizes in the past 3 months $[56,57]$. Parent physical activity will be assessed using the validated Arizona Activity Frequency Questionnaire, a self-administered 59-item questionnaire in which participants report whether they performed each activity during the past 28 days [58]. Primary outputs include daily energy expenditure (kilocalories), number of hours per day spent in each activity, and number of activities reported for each category.

The home food and physical activity environment will be assessed using the Family Nutrition and Physical Activity Tool, a 21-item survey of the family home environment and practices associated with children's risk of becoming overweight. Parents will use the tool to report the frequency of breakfast and family meals, modeling of nutrition, nutrient dense foods and high calorie beverages, restriction and reward, parent modeling physical activity, child's physical activity, screen time, TV in bedroom, and sleep routines [59, 60].

Given the considerable impact of social and environmental factors on participants' ability to follow through with health recommendations, we will collect demographic and socioenvironmental data associated with T2DM risk and health disparities (e.g., food insecurity, housing stability, culture and language, community support, socioeconomic status, financial barriers, literacy and numeracy) using the PRAPARE questionnaire developed for use in health care settings, and already routinely implemented by El Rio. All surveys will be made available in English and Spanish.

The intention-to-treat principle will be used for all the analyses. Differences in participants' baseline characteristics between the two groups will be evaluated by a twosample $t$-test for continuous outcomes and by Chisquare test or Fisher's exact test for categorical outcomes. Initial analyses will compare the changes between baseline and follow-up between the intervention versus wait-list control groups using two-sample sample $t$-tests. Subsequently, a mixed-model analysis of covariance including treatment group, time, and baseline value of the outcome will be used to assess the effects of intervention at 13 and 26 weeks. Participants will be treated as a random effect nested within group. An interaction effect between time and treatment group will be assessed first. If there is no interaction effect, the overall treatment difference will be assessed. Otherwise, the treatment difference will be assessed at each time point. In order to measure the relative cost-effectiveness of these programs, we will also explore costs associated with implementation by El Rio staff.

Given the feasibility focus of this study, we will also evaluate whether aspects of the intervention work as intended, including participant acceptability (participant satisfaction) and program relevance (rated using brief surveys of the relevance of the intervention to daily life, promoters and barriers to program attendance and engagement, the degree to which families report using the intervention to guide behavioral choices, and surveys of lifestyle coaches trained to deliver the intervention). We will assess adoption by El Rio and integration with the existing clinical setting using semi-structured interviews with El Rio wellness staff and administrators and feasibility (of delivery by providers and FQHC) by examining recruitment, enrollment, and retention rates, session attendance data, and observed participant engagement with intervention activities. Fidelity will be assessed through observation of research staff following an established rubric, and program costs will be evaluated using a bottom-up micro-costing approach (including direct medical and non-medical costs including personnel gross hourly salaries, intervention material costs, and overhead costs related to use of facilities for prevention services will be tracked and analyzed in partnership with El Rio's data team members). We will also explore the potential for replication and dissemination using semistructured interviews with El Rio wellness staff assigned to coordinate and deliver the program, and administrators and advisory board members who understand how to align the intervention with El Rio's fiscal and strategic plans, and who have relationships with other FQHCs in Arizona and nationally. Our a priori focus on factors 
influencing sustainability (e.g., reach, integration with other health/wellness programs, institutionalization) beyond the research funding period will remain a major consideration throughout the proposed study.

\section{Discussion}

There is a growing need to develop and evaluate prevention initiatives that focus on lifestyle modification for youth and their families at highest risk for T2DM. We will, in collaboration with an FQHC, create a T2DM risk-reducing intervention program (EPIC El Rio Families) for delivery to mothers at high risk for T2DM because of their history of GDM and/or prediabetes, and who have school-aged children who are also at risk. The intervention is unique in that it was designed at its inception to integrate with the clinical operation of an FQHC and developed in partnership with client-facing health and wellness FQHC staff. FQHCs by their nature are well suited to implement interventions for populations who have historically experienced significant barriers to accessing quality health care. Past diabetes prevention studies implemented in medical centers were efficacy trials that gave minimal consideration to the cost of implementation [22-24]. These researchoriented programs were then adapted to be used in community settings [35]. As a result, they are often not optimized for dissemination in large volume primary care settings. Moreover, very few have simultaneously targeted mothers and their children at risk for T2DM. By designing the program to be implemented in an extant FQHC facility that cares for families, we will be able to answer several questions that are crucial to developing an effective translation model that can be applied across the FQHC system. The results from this study will be critical in developing a T2DM prevention model that can be implemented and scaled across FQHC settings to effectively mitigate this burgeoning problem in medically underserved youth and adult. In this context, using the FQHC system to implement diabetes prevention programs in populations that have an increased burden from T2DM is an important public health initiative.

\section{Supplementary Information}

The online version contains supplementary material available at https://doi. org/10.1186/s12889-021-10392-w.

Additional file 1.

Additional file 2

\section{Abbreviations}

EPIC: Encourage, Practice and Inspire Change; DPP: Diabetes Prevention Program; GDM: Gestational diabetes mellitus; T2DM: Type 2 diabetes mellitus; FQHC: Federally Qualified Health Center; CDC: Centers for Disease Control and Prevention; YMCA: Young Men's Christian Association; CLIA: Clinical Laboratory Improvement Amendments; HbA1c: Hemoglobin A1c; BMI: Body Mass Index

\section{Acknowledgements}

The authors wish to thank Ms. Shelley Whitlatch, Dr. Joy Mockbee, Ms. Holly Bryant, Ms. Griselda Ruiz-Braun, Ms. Eliza Short, and Ms. G. Anaid Serrano for their contributions.

\section{Authors' contributions}

MDH and DGM conceived of the study. MDH, DGM, DJR initiated the study design, and RMB, KP, and KJ helped with implementation. MDH and DGM are grant holders. DJR provided statistical expertise in clinical trial design. All authors contributed to refinement of study protocol and approved the final manuscript.

\section{Funding}

Research reported in this publication was supported by the National Institute Of Diabetes And Digestive And Kidney Diseases of the National Institutes of Health under Award Number R34DK118486. The content is solely the responsibility of the authors and does not necessarily represent the official views of the National Institutes of Health.

\section{Availability of data and materials}

Not applicable.

\section{Ethics approval and consent to participate}

An Institutional Review Board responsible for human subjects research at The University of Arizona reviewed this research project and found it to be acceptable, according to applicable state and federal regulations and University policies designed to protect the rights and welfare of participants in research, Protocol 1810033478A011. Written consent (adults) and assent

(children) will be obtained prior to participation.

Consent for publication

Not applicable.

\section{Competing interests}

The authors (DGM, KP, KJ, DJR, RMB, MDH) declare that they have no competing interests.

\section{Author details}

${ }^{1}$ University of Arizona Health Sciences Center for Border Health Disparities, 1295 North Martin Ave., P.O. Box 210202, Tucson, AZ 85721, USA.

${ }^{2}$ Department of Nutritional Sciences, College of Agriculture \& Life Sciences, The University of Arizona, 1177 E. 4th Street, Shantz Building, Room 328, Tucson, AZ 85721, USA. ${ }^{3}$ University of Arizona Collaboratory for Metabolic Disease and Prevention, Abrams Public Health Center, 3950 S. Country Club Rd, Tucson, AZ 85714, USA. ${ }^{4}$ Family and Child Wellness at El Rio Community Health Center, 450 W Paseo Redondo, Tucson, AZ 85701, USA. ${ }^{5}$ Department of Epidemiology and Biostatistics, Mel and Enid Zuckerman College of Public Health, The University of Arizona, 1295 N. Martin Ave., P.O. Box 245210,

Tucson, AZ 85724, USA.

Received: 2 February 2021 Accepted: 5 February 2021

Published online: 12 February 2021

\section{References}

1. Narayan KM, Boyle JP, Geiss LS, Saaddine JB, Thompson TJ. Impact of recent increase in incidence on future diabetes burden: U.S., 2005-2050. Diabetes Care. 2006;29(9):2114-6.

2. Centers for Disease Control and Prevention. National Diabetes Statistics Report. Edited by Centers for Disease Control and Prevention. Atlanta, 2020. https://www.cdc.gov/diabetes/data/statistics-report/index.html Accessed 31 Jan 2021

3. Hamman RF, Bell RA, Dabelea D, D'Agostino RB Jr, Dolan L, Imperatore G, Lawrence JM, Linder B, Marcovina SM, Mayer-Davis EJ, et al. The SEARCH for diabetes in youth study: rationale, findings, and future directions. Diabetes Care. 2014;37(12):3336-44.

4. Epstein LH, Valoski A, Wing RR, McCurley J. Ten-year outcomes of behavioral family-based treatment for childhood obesity. Health Psychol. 1994;13(5): 373-83.

5. Wiffley DE, Tibbs TL, Van Buren DJ, Reach KP, Walker MS, Epstein LH. Lifestyle interventions in the treatment of childhood overweight: a meta- 
analytic review of randomized controlled trials. Health Psychol. 2007;26(5): 521-32.

6. Baranowski T, Baranowski J, Cullen K, Hingle M, Hughes S, Jago R, Ledoux T, Mendoza J, Nguyen TT, O'Connor T, Thompson D, Watson K. Chapter 35 Problems and possible solutions for interventions among children and adolescents. In: O'Dea JA, Eriksen M, editors. Childhood Obesity Prevention: International Research, Controversies and Interventions. 2010. Published to Oxford Scholarship Online: January 2011. https://doi.org/10.1093/acprof:oso/ 9780199572915.001.0001.

7. Baranowski TCK, Nicklas T, Thompson D, Baranowski J. School-based obesity prevention: a blueprint for taming the epidemic. Am J Health Behav. 2002; 26(6):486-93.

8. Foster GD, Linder B, Baranowski T, Cooper DM, Goldberg L, Harrell JS, Kaufman F, Marcus MD, Trevino RP, et al. A school-based intervention for diabetes risk reduction. N Engl J Med. 2010;363(5):443-53.

9. Katz DL, O'Connell M, Njike VY, Yeh MC, Nawaz H. Strategies for the prevention and control of obesity in the school setting: systematic review and meta-analysis. Int J Obes. 2008;32(12):1780-9.

10. Lau DC, Douketis JD, Morrison KM. Canadian clinical practice guidelines on the management and prevention of obesity in adults and children [summary]. CMAJ. 2007;176(8):1-13.

11. Blotsky AL, Rahme E, Dahhou M, Nakhla M, Dasgupta K. Gestational diabetes associated with incident diabetes in childhood and youth: a retrospective cohort study. CMAJ. 2019;191(15):E410-7.

12. Huang $\Pi$, Ferris $E$, Tripathi $D$. An integrative analysis of the effect of lifestyle and pharmacological interventions on glucose metabolism in the prevention and treatment of youth-onset type 2 diabetes. Curr Diab Rep. 2016;16(8):78.

13. American Diabetes Association. Improving care and promoting health in populations: standards of medical care in diabetes-2020. Diabetes Care. 2020;43(Suppl 1):S7-S13.

14. Boney CM, Verma A, Tucker R, Vohr BR. Metabolic syndrome in childhood: association with birth weight, maternal obesity, and gestational diabetes mellitus. Pediatrics. 2005;115(3):e290-6.

15. Sacks DA, Hadden DR, Maresh M, Deerochanawong C, Dyer AR, Metzger BE, Lowe LP, Coustan DR, Hod M, Oats JJ, et al. Frequency of gestational diabetes mellitus at collaborating centers based on IADPSG consensus panel-recommended criteria: the hyperglycemia and adverse pregnancy outcome (HAPO) study. Diabetes Care. 2012;35(3):526-8.

16. Lawrence JMCR, Chen W, Sacks DA. Trends in the prevalence of preexisting diabetes and gestational diabetes mellitus among a racially-ethnically diverse population of pregnant women, 1999-2005. Diabetes Care. 2008; 31(5):899-904.

17. Dabelea D. The predisposition to obesity and diabetes in offspring of diabetic mothers. Diabetes Care. 2007;30(Suppl 2):S169-74.

18. Hedderson MM, Darbinian JA, Ferrara A. Disparities in the risk of gestational diabetes by race-ethnicity and country of birth. Paediatr Perinat Epidemiol. 2010;24(5):441-8.

19. Zhou T, Sun D, Li X, Heianza Y, Nisa H, Hu G, Pei X, Shang X, Oi L. Prevalence and Trends in Gestational Diabetes Mellitus among Women in the United States, 2006-2016. Diabetes. 2018;67(Suppl1). https://diabetes.dia betesjournals.org/content/67/Supplement_1/121-OR.

20. Dabelea D, Mayer-Davis EJ, Lamichhane AP, D'Agostino RB Jr, Liese AD, Vehik KS, Narayan KM, Zeitler P, Hamman RF. Association of intrauterine exposure to maternal diabetes and obesity with type 2 diabetes in youth: the SEARCH Case-Control Study. Diabetes Care. 2008;31(7):1422-6.

21. Sartorius $T$, Staiger $H$, Ketterer $C$, Heni M, Machicao F, Guilherme A, Grallert $H$, Schulze MB, Boeing $H$, Stefan $N$, et al. Association of common genetic variants in the MAP4K4 locus with prediabetic traits in humans. PLOS One. 2012;7(10):e47647

22. Knowler WC, Barrett-Connor E, Fowler SE, et al. Reduction in the incidence of type 2 diabetes with lifestyle intervention or metformin. N Engl J Med. 2002;346(6):393-403

23. Knowler WC for the Diabetes Prevention Program Research Group. 10-year follow-up of diabetes incidence and weight loss in the diabetes prevention program outcomes study. Lancet. 2009;374(9702):1677-86.

24. Lindström J, llanne-Parikka P, Peltonen M, Aunola S, Eriksson JG, Hemiö K, Hämäläinen $H$, Härkönen $P$, Keinänen-Kiukaanniemi S, Laakso $M$, et al. Sustained reduction in the incidence of type 2 diabetes by lifestyle intervention: follow-up of the Finnish diabetes prevention study. Lancet. 2006;368(9548):1673-9.
25. Golan M, Crow S. Parents are key players in the prevention and treatment of weight-related problems. Nutr Rev. 2004;62(1):39-50.

26. Golan M, Kaufman V, Shahar DR. Childhood obesity treatment: targeting parents exclusively v. parents and children. Br J Nutr. 2006:95(5):1008-15.

27. Golan M, Weizman A. Familial approach to the treatment of childhood obesity: conceptual model. J Nutr Educ. 2001:33(2):102-7.

28. Golan M, Crow S. Targeting parents exclusively in the treatment of childhood obesity: long-term results. Obes Res. 2004;12:357-61.

29. Golan M, Weizman A, Apter A, Fainaru M. Parents as the exclusive agents of change in the treatment of childhood obesity. Am J Clin Nutr. 1998;95: 1008-15.

30. Wilfley DE, Vannucci A, White EK. Early intervention of eating- and weightrelated problems. J Clin Psychol Med Settings. 2010;17(4):285-300.

31. Epstein LH, Paluch RA, Roemmich JN, Beecher MD. Family-based obesity treatment, then and now: twenty-five years of pediatric obesity treatment. Health Psychol. 2007;26(4):381-91.

32. Hingle MD, Turner T, Going S, Ussery C, Roe DJ, Saboda K, Kutob R, Stump C. Feasibility of a family-focused YMCA-based diabetes prevention program in youth: The E.P.I.C. Kids (Encourage, Practice, and Inspire Change) Study. Prev Med Rep. 2019;14:100840.

33. Hingle MD, Turner T, Kutob R, Merchant N, Roe DJ, Stump C, Going SB. The EPIC Kids Study: a randomized family-focused YMCA-based intervention to prevent type 2 diabetes in at-risk youth. BMC Public Health. 2015:15:1253.

34. Ackermann RT, Finch EA, Brizendine E, Zhou H, Marrero DG. Translating the Diabetes Prevention Program into the community. The DEPLOY Pilot Study. Am J Prev Med. 2008;35(4):357-63.

35. Albright AL, Gregg EW. Preventing type 2 diabetes in communities across the US: the National Diabetes Prevention Program. Am J Prev Med. 2013; 44(4 Suppl 4):S346-51.

36. O'Connor EA, Evans CV, Burda BU, Walsh ES, Eder M, Lozano P. Screening for obesity and intervention for weight management in children and adolescents: evidence report and systematic review for the US preventive services task force. JAMA. 2017;317(23):2427-44.

37. Rivers $P$, Hingle M, Ruiz-Braun G, Blew R, Mockbee J, Marrero D. Adapting a family-focused diabetes prevention program for a federally qualified health center: a qualitative report. Diabetes Educ. 2020;46(2):161-8.

38. Spruijt-Metz D, O'Reilly GA, Cook L, Page KA, Quinn C. Behavioral contributions to the pathogenesis of type 2 diabetes. Curr Diab Rep. 2014: 14(4):475

39. Greaves CJ, Sheppard KE, Abraham C, et al. Systematic review of reviews of intervention components associated with increased effectiveness in dietary and physical activity interventions. BMC Public Health. 2011;11(119). https:// doi.org/10.1186/1471-2458-11-119.

40. Michie S, Abraham C, Whittington C, McAteer J, Gupta S. Effective techniques in healthy eating and physical activity interventions: a metaregression. Health Psychol. 2009;28(6):690-701.

41. Golley RK, Hendrie GA, Slater A. Corsini N/ interventions that involve parents to improve children's weight-related nutrition intake and activity patterns what nutrition and activity targets and behaviour change techniques are associated with intervention effectiveness? Obes Rev. 2011;12(2):114-30.

42. Centers for Disease Control and Prevention. National Diabetes Prevention Program, 2019. https://www.cdc.gov/diabetes/prevention/index.html Accessed 31 Jan 2021.

43. Finch EA, Kelly MS, Marrero DG, Ackermann RT. Training YMCA wellness instructors to deliver an adapted version of the diabetes prevention program lifestyle intervention. Diabetes Educ. 2009;35(2):224-8 232.

44. American Diabetes Association. Prevention or delay of type 2 diabetes: standards of medical care in diabetes-2020. Diabetes Care. 2020;43(Suppl 1): S32-6.

45. World Health Organization. Obesity and overweight: Key Facts. https://www who.int/news-room/fact-sheets/detail/obesity-and-overweight Accessed 31 Jan 2021.

46. Kuczmarski RJ, Ogden CL, Grummer-Strawn LM, Flegal KM, Guo SS, Wei R, Mei Z, Curtin LR, Roche AF, Johnson CL. CDC growth charts: United States. Adv Data. 2000;314:1-27

47. Kakinami L, Henderson M, Chiolero A, Cole TJ, Paradis G. Identifying the best body mass index metric to assess adiposity change in children. Arch Dis Child. 2014:99(11):1020-4.

48. James PA, Oparil S, Carter BL, Cushman WC, Dennison-Himmelfarb C, Handler J, Lackland DT, LeFevre ML, MacKenzie TD, Ogedegbe O, et al. Evidence-based guideline for the management of high blood pressure in 
adults: report from the panel members appointed to the Eighth Joint National Committee. JAMA. 2014;311(5):507-20.

49. Flynn JT, Falkner BE. New clinical practice guideline for the management of high blood pressure in children and adolescents. Hypertension. 2017;70(4): 683-6.

50. Feskanich D, Sielaff BH, Chong K, Buzzard IM. Computerized collection and analysis of dietary intake information. Comput Methods Prog Biomed. 1989; 30(1):47-57.

51. Krebs-Smith SM, Pannucci TE, Subar AF, Kirkpatrick SI, Lerman JL, Tooze JA, Wilson MM, Reedy J. Update of the healthy eating index: HEl-2015. J Acad Nutr Diet. 2018;118(9):1591-602.

52. Reedy J, Lerman JL, Krebs-Smith SM, Kirkpatrick SI, Pannucci TE, Wilson MM, Subar AF, Kahle LL, Tooze JA. Evaluation of the healthy eating index-2015. J Acad Nutr Diet. 2018;1 18(9):1622-33.

53. Saint-Maurice PF, Welk GJ. Validity and calibration of the youth activity profile. PLoS One. 2015;10(12):e0143949.

54. Owens JA, Spirito A, McGuinn M. The Children's Sleep Habits Questionnaire (CSHQ): psychometric properties of a survey instrument for school-aged children. Sleep. 2000;23(8):1043-51.

55. Morris NM, Udry JR. Validation of a self-administered instrument to assess stage of adolescent development. J Youth Adolesc. 1980;9(3):271-80.

56. Thomson CA, Giuliano A, Rock CL, Ritenbaugh CK, Flatt SW, Faerber S, Newman V, Caan B, Graver E, Hartz V, et al. Measuring dietary change in a diet intervention trial: comparing food frequency questionnaire and dietary recalls. Am J Epidemiol. 2003;157(8):754-62.

57. Martinez ME, Marshall JR, Graver E, Whitacre RC, Woolf K, Ritenbaugh C, Alberts DS. Reliability and validity of a self-administered food frequency questionnaire in a chemoprevention trial of adenoma recurrence. Cancer Epidemiol Biomark Prev. 1999;8(10):941-6.

58. Staten LK, Taren DL, Howell WH, Tobar M, Poehlman ET, Hill A, Reid PM, Ritenbaugh C. Validation of the Arizona Activity Frequency Questionnaire using doubly labeled water. Med Sci Sports Exerc. 2001;33(11):1959-67.

59. Ihmels MA, Welk GJ, Eisenmann JC, Nusser SM. Development and preliminary validation of a Family Nutrition and Physical Activity (FNPA) screening tool. Int J Behav Nutr Phys Act. 2009;6:14.

60. Ihmels MA, Welk GJ, Eisenmann JC, Nusser SM, Myers EF. Prediction of BMI change in young children with the family nutrition and physical activity (FNPA) screening tool. Ann Behav Med. 2009;38(1):60-8.

\section{Publisher's Note}

Springer Nature remains neutral with regard to jurisdictional claims in published maps and institutional affiliations.

Ready to submit your research? Choose BMC and benefit from:

- fast, convenient online submission

- thorough peer review by experienced researchers in your field

- rapid publication on acceptance

- support for research data, including large and complex data types

- gold Open Access which fosters wider collaboration and increased citations

- maximum visibility for your research: over $100 \mathrm{M}$ website views per year

At $\mathrm{BMC}$, research is always in progress.

Learn more biomedcentral.com/submissions 